\title{
Educaçáo ambiental e princípio de sustentabilidade no mundo moderno
}

\section{Environmental education and sustainability in modern times}

\begin{abstract}
Resumo
O presente estudo tem como objetivo discutir a educação ambiental, considerando esta como uma problemática inerente ao desenvolvimento global. Para tanto, analisam-se dispositivos, como comitês e documentos, que, no século XX, buscaram minimizar o impacto do homem moderno na natureza. Após tal levantamento, selecionamse idéias que corroborem para o entendimento da educaçáo ambiental na atualidade, a fim de se questionar os inconvenientes elementos transformadores da educação pela/para natureza.
\end{abstract}

Palavras-chave: Homem, Natureza, Educação Ambiental, Desenvolvimento Sustentável.

\section{Abstract}

The following study aims to discuss the environmental education as a intrinsic problem for the global development. In order to accomplish such study, committees and documents, which tried to minimize the human impact in nature, were analyzed. After studying the data, we selected some ideas to understand the environmental education nowadays, in order to discuss the elements that change the education for/to nature.

Keywords: Human being, Nature, Environmental Education, Susteinable Development.

${ }^{1}$ Docente da disciplina de Pediatria e Puericultura do curso de Medicina do Centro Universitário de Volta Redonda, e mestranda em Ensino em Ciências da Saúde e do Meio Ambiente

${ }^{2}$ Acadêmica de Medicina do Centro Universitário de Volta Redonda. 


\section{INTRODUÇÃO}

Para que se desenvolva a temática da educação ambiental, é fundamental que se considere dois fatores: hoje, vive-se em grandes centros urbanos, que têm crescimento demográfico continuo, como também se tem mais acelerado o desenvolvimento tecnológico. Baseando-se nessa premissa é que se propóe uma reflexão acerca da degradação permanente de recursos naturais e de ecossistemas.

Atualmente, pensar em educação ambiental requer a consideração de diferentes atores sociais, além, é claro, da comunidade acadêmica. $O$ universo educativo para a questão da preservação ambiental já não se restringe aos cientistas e pesquisadores, está presente no âmbito das instituiçóes públicas e privadas, ou seja, escolas, organizaçóes não-governamentais, empresas, etc.

Logo, a produção de conhecimento em educação ambiental sofreu intensas modificaçóes. E, por conseguinte, se constituiu como uma problemática, já que os princípios desenvolvidos nessa área da educação passaram a atender diversas ideologias, estas pertinentes a política, a economia, a responsabilidade social, dentre outras áreas que fizeram da educação ambiental o seu diferencial competitivo, o seu recurso para a aceitação popular, como se poderá perceber a seguir.

\section{EDUCAÇÃO AMBIENTAL: ASPECTOS GERAIS SOBRE A PERSPECTIVA DA PRESERVAÇÃO DE RECURSOS NATURAIS}

Muito se tem discutido a respeito da degradação contínua do meio ambiente e de seu ecossistema por inúmeras práticas sociais, o que remete, certamente, a uma análise do papel da educação ambiental. Atualmente, a questão ambiental aplica-se a um conjunto de atores presentes no universo educativo. Cabe, por isso, destacar a função de diversas áreas do conhecimento da comunidade acadêmica, bem como de profissionais ligados a outros setores sociais.

Tendo em vista a demanda por preservação ambiental em face dos grandes fenômenos que têm atormentado a sociedade, é pertinente se ressaltar o desafio que se impóe acerca de uma educação ambiental crítica e inovadora, que compreenda ainda dois níveis o formal e o informal, como preceitua a lei ${ }^{\circ}$ 9.795/99 que dispóe sobre a educação ambiental e cria a Política Nacional de Educação Ambiental no Brasil. Educaçáo ambiental como ato político capaz de promover a transformação social.

Logo, entende-se a necessidade de uma ação que compreenda sociedade e meio ambiente como um todo indecomponível, já que os recursos naturais são bens que, de certa forma, se esgotam e que o homem é o principal consu- midor dos mesmos e, ainda, o primeiro agente degradador.

Vale mencionar neste artigo aspectos históricos a respeito da preservação ambiental. Notoriamente, a Revolução Industrial foi o marco simultaneamente da exploração e da destruição desordenada do meio ambiente. A partir do século XVIII, desencadearam-se grandes prejuízos aos ecosssitemas. Com o desenvolvimento das economias, as modificaçóes do meio foram transcorrendo, oriundas de tecnologias poluentes e impactantes (CMMAD, 2001), sem um mínimo de responsabilidade para com a preservação de elementos essenciais à vida humana.

Terras, águas, vegetais, animais e seres humanos foram atropelados por uma idéia mal definida de progresso. No fundo, a humanidade foi vítima de uma irrupção de certas ondas do poder, com a utilizaçáo "irracional" das tecnologias científicas, sem controle do Estado e das agências sociais.

$\mathrm{O}$ crescente aumento de parques industriais, sem projetos de implantação que cuidassem das questôes urbanísticas locais, acabaram por resultar em acúmulo e concentração de resíduos e lixos em solos despreparados ou em canais marítimos ou fluviais.

Esse cenário foi intensificado conforme o aparecimento de locomotivas, navios a motor e outros maquinários com funcionamento à base de óleo diesel. Apesar dessas descobertas tecnológicas otimizarem os resultados dos ciclos produtivos em geral, afetavam substancialmente os recursos naturais do meio ambiente.

Constatou-se, a seguir, uma permanente evolução da produçáo e dos avanços tecnológicos que conduziram o homem a patamares elevados de confortos, praticidades, rapidez, etc., baseados, contudo, em desenvolvimentos inconscientes acerca do caráter finito dos recursos naturais do planeta. Verificou-se que a própria vivência de naçóes desenvolvidas industrialmente revela danos incalculáveis à natureza e ao meio ambiente, que resultavam na extinçáo de recursos vitais à sobrevivência do planeta. $\mathrm{O}$ crescimento dessa situação estimulou uma nova abordagem acerca dos eminentes impactos ambientais, que passaram a gerar preocupaçôes em todo o mundo. (ANDRADE et. al., 2002)

Por volta dos anos 1960, os assuntos ligados à ecologia passaram a ser tratados com mais evidência. Surgiram preocupaçóes em torno de temas interligados ao assunto, como saúde e segurança. Diversos eventos de âmbito mundial, realizados desde então, passaram a sinalizar o crescente interesse pela questão. Começaram, então, a ser debatidos os termos de um desenvolvimento que preservasse a sustentação do planeta. Iniciou-se uma grande mobilização de autoridades mundiais a favor de soluçóes ambientalmente melhores, a partir de conferências, encontros e açóes nesse sentido.

O princípio desse movimento deu-se por meio de uma conferência sobre a biosfera, realizada 1968, na França. A 
esse evento compareceram especialistas em ciências naturais de todo o mundo. Posteriormente, o Clube de Roma, no início da década de 70, publicou informes em documento intitulado "Limites do Crescimento", que relatava os impactos ao meio ambiente decorrentes de atividades industriais. (ECOECO, 2004)

Seguindo a evoluçáo dos acontecimentos, em 1972, um encontro para a "Declaraçáo sobre o Meio Ambiente Humano" reuniu na Suécia, Estocolmo, autoridades e representantes de governos de todo o mundo para discussáo dos problemas que assolavam o meio ambiente. Este evento foi considerado um marco para aceitação do mercado em geral, liderado por desenvolvimentistas, sobre as questóes de preservação do meio ambiente.

No entanto, a evolução da idéia de sustentabilidade deveria propor modelos de gestão que relevassem a harmonia entre desenvolvimento e natureza, incorporando, no ambiente de decisōes empresariais e governamentais, os conceitos de Desenvolvimento Sustentável, Responsabilidade Social, Atuação Responsável, Qualidade de Vida e Sobrevivência Humana.

Da Conferência de Estocolmo resultou um documento contemplando 26 princípios acerca da preservação do meio ambiente. A partir daí surgiram diversas instituições e grupos com o mote de defesa do meio ambiente. Alguns países como a França, Alemanha, Dinamarca, Noruega, Finlândia e Holanda estabeleceram novas regras e legislaçôes ambientais após esse evento, dando impulso a mudanças organizacionais da empresa.

No início da década de 80, a Organização das Naçóes Unidas convocou a Comissão Mundial para assuntos do Meio Ambiente e Desenvolvimento (CMMAD) e motivou a elaboração de um relatório sobre a qualidade do meio ambiente de abrangência mundial. O documento foi intitulado Relatório Nosso futuro Comum, também conhecido como Relatório Brundtland (uma maneira de homenagear a ex-primeira-ministra da Noruega, Gro Harlem Brundtland, presidente da Comissão Mundial de Meio Ambiente e Desenvolvimento em 1987, ocasião na qual o documento foi redigido).

Nesse momento, definiu-se o conceito de desenvolvimento sustentável como aquele que atende às necessidades das geraçôes atuais sem se comprometer a capacidade de as futuras geraçóes terem suas próprias necessidades atendidas. O documento destaca, ainda, veementemente, a adoção mundial de políticas concretas, específicas para questóes ambientais como sendo imprescindível ao futuro do planeta. Chamou-se a atenção para a delimitação necessária entre tecnologia e o meio ambiente. Defendia-se, por consequência, a idéia de que a economia e a ecologia podem ser pensadas juntas e, nesse sentido, instigou-se a inclusão do meio ambiente na política econômica, ou melhor, nos processos de decisáo dos setores sociais.

Percebeu-se, assim, que cada vez mais a sociedade tomava consciência da necessidade em se preservar os recursos ambientais e desenvolver formas alternativas para a exploração ambiental, recompensando constantemente aquilo que é extraído apenas para conforto dos grupos sociais. (CMMAD, 2001, p. 78)

A idéia de que a natureza é uma fonte de recursos finitos e não gratuitos, proporcionou um novo enfoque à economia e à exploração econômica. Constata-se, hoje em dia, a necessidade de racionalizar e otimizar a utilização dos recursos naturais dentro de uma visão de longo prazo, levando-se em conta os princípios da conservação, reciclagem, poupança e precaução.

Prosseguindo a evoluçáo dos conceitos voltados à preservação do meio-ambiente, em 1991, na Conferência Mundial da Indústria sobre a Gestão do Ambiente, foi divulgada a Carta Empresarial para o Desenvolvimento Sustentável, elaborada pela Câmara de Comércio Internacional (CCI). A divulgação dessa carta possibilitou nortear as empresas de todo o mundo que se comprometeram e cumpriram os princípios relativos à gestáo do ambiente. Esse documento representou, por conseguinte, uma importância vital para o desenvolvimento sustentável.

Quanto ao meio acadêmico, destaca-se, na década de 70, nos Estados Unidos, a instituição da sociologia ambiental que tratou das mutuas relaçóes estabelecidas entre sociedade e natureza, entre homem e seu meio natural. Essa ramificação da sociologia veio de encontro ao ideal de desenvolvimento econômico que tinha a degradação ambiental como consequência inevitável do progresso. Assim, a ideologia ambientalista foi vista como grande oponente do desenvolvimento econômico global. (HERCULANO, 2000).

A sociologia ambiental se estabeleceu, em meio aos contratempos do desenvolvimento nas áreas tecnológica, econômica e industrial, como uma reflexão acerca da urgência de açôes a favor de problemas ambientais provocados por esses setores, principalmente. Todavia, vale destacar o fato de que tal vertente sociológica tenha se transformado nos anos 80 , passando a perceber a degradação ambiental não mais como um problema puramente estético, mas sim de saúde pública.

Porém, não foi exatamente a sociologia ambiental que deu dimensão global a questão da preservação dos recursos naturais, e sim a Conferência da Organização das Naçôes Unidas para o Meio Ambiente e o Desenvolvimento - CNUMAD ou UNCED, realizada no Rio de Janeiro, em 1992. Nesse momento, foi criada a Comissão para o Desenvolvimento Sustentável e o Fundo Geral para o Meio Ambiente, justamente, por conta de alteraçóes climáticas causadas pela produção humana. 
A partir daí, surgiram grupos de estudos acadêmicos e comissóes intergovernamentais, o que acabou por relacionar cientistas e sociedade civil e promover pesquisas consideráveis acerca dos impactos produzidos pelo homem na natureza, mais precisamente, daquilo que dá origem ao aquecimento global.

Foi, ainda, nos anos 90, que a Associação Internacional de Sociologia fundou um comitê de pesquisa, o Research Committee 24, que teve o apoio de estudos de outras áreas da Sociologia. Tal promoção redundou a implantação de diversos cursos de pós-graduação no Brasil, bem como a criação do GT 04 - Ecologia e Sociedade, que passaram a se dedicar especificamente à temática ambiental.

Afirma-se que tais bases teóricas redundaram, na sociedade moderna, em especial no Brasil, uma "sensibilização ecológica”, como assevera Grün (1996, p. 19). O autor, apoiado em Pádua (1992), cita alguns dos fatores que, talvez, sejam tidos no país como referência para tal comportamento. São eles: a própria ordem global a respeito de ecologia; a notória relação entre baixa qualidade de vida nos países subdesenvolvidos ou em desenvolvimento e a degradação socioambiental; a imagem e a função estratégica assumida pela Brasil diante do cenário mundial; a devastação da maior reserva biológica do mundo, a floresta amazônica; e, principalmente, a conscientização nacional acerca dos causadores de fenômenos naturais catastróficos que têm devastado cidades no Brasil e no mundo.

Assim, o medo em relação ao meio ambiente, não só no Brasil, mas também no globo, vem disseminando a idéia de preservação imediata dos recursos naturais. Tal movimento traz uma relevante perspectiva para o contexto social, a de que o ambientalismo não é mais objeto de estudo e de valorização somente da comunidade acadêmica, mas sim de todos aqueles - sociedade, governo, empresas, etc. que atuam "livremente" no meio ambiente.

Desde que a educação ambiental deixou de se ser proposta da Sociologia para se tornar perspectiva social e, ainda, política de Estado, passou a atingir todas as classes sociais e não somente a intelectualizada, a classe média, segundo Grün (1996). E, certamente, sua fundamentação foi transfigura$\mathrm{da}$, ao passo em que se revertiu da lógica capitalista e passou a atender a demanda de avanços tecnológicos.

Se se pensar nas últimas décadas como períodos de construção da educação ambiental, percebe-se que houve uma movimentação favorável a conceitualização do tema, embora ainda não se tenha uma definição precisa haja vista tamanha a complexidade da área. Todavia, hoje, se tem solidificado um outro consenso e uma nova necessidade da preservação, o que se pode denominar de "ética antropocêntrica”, como diz Grün (1996, p. 23), e não necessariamente "manifestação ecológica".
Partindo desse pressuposto e apoiado nas idéias do filósofo Holmes Rolston III, as quais destituía do homem a posse da natureza, Grün (1996) entende que não são exatamente "nossos" os recursos naturais, como também afirma que o homem - imbuído desse sentimento de propriedade - não tem consciência real do valor da natureza.

Modernamente, se têm tais recursos como material imprescindível capaz de dar sustentabilidade a toda tecnologia desenvolvida até o momento e, o homem, como simples usuário dessa ferramenta, apresenta-se preocupado com a extinção dessas fontes naturais. Isso porque, nos tempos atuais, a informação assumiu um papel considerável na interrelação entre sujeitos e entre naçôes. Nesse sentido, a educação para a cidadania, desenvolvida no ciberespaço, na multimídia, na Internet, passou a implicar motivaçáo e sensibilização das fontes primárias da tecnologia.

Logo, educação ambiental é entendida mais como um instrumento a serviço do poder, da colonização da subjetividade e dos desejos humanos, como bem afirma Grün (1996). Mais precisamente, a educação ambiental, hoje, é relacionada ao tema desenvolvimento sustentável e percebida como condição sine qua non para se modificar a estrutura econômica global, além, é claro, de se garantirem ações favoráveis à redução do quadro de degradação ambiental.

Mas, insiste-se na premissa de que a educação ambiental, no atual contexto social, não seja suficiente, já que essa se mostra, justamente, como uma ferramenta aplicada na mediação entre culturas, comportamentos e interesses de grupos sociais diversos, a fim de se constituir transformaçôes sociais pré-definidas, favorecendo, certamente, a determinados grupos políticos.

No entanto, é oportuno que se ressaltem os princípios fundamentais da educação ambiental. Educar, nesse sentido, implica oferecer métodos eficazes e pertinentes ao desenvolvimento de práticas sociais centradas, essencialmente, no conceito de natureza, e não na lógica capitalista. Deve, ainda, a educação ambiental promover a reflexão sobre as dimensôes do progresso humano, sobre o impacto que este causa ao meio ambiente em detrimento do desenvolvimento tecnológico, em especial.

Deve-se reconhecer a educação ambiental como um processo político dinâmico, em permanente construção, orientado por valores baseados na transformação social. Nesse sentido, a iniciativa das Naçóes Unidas de implementar a Década da Educação para o Desenvolvimento Sustentável (2005-2014) e o de 2010 como o Ano Internacional da Biodiversidade.ano reforçou mundialmente a sustentabilidade a partir da educação.

As mudanças climáticas ainda compreendem o maior desafio ambiental e de desenvolvimento do século XXI. As Conferências das Partes sobre Clima (COPs) existem desde 
1995, quando os representantes dos países signatários da Convenção-Quadro das Nações Unidas sobre Mudanças Climáticas passaram a se reunir anualmente. A $15^{\text {a Confe- }}$ rência das Partes (COP 15) da Convenção-Quadro das Naçôes Unidas sobre Mudanças do Clima, realizada em 2009 em Copenhagen, Dinamarca, já é considerada uma das mais importantes reuniôes entre governos de todo o mundo. Olhares atentos de todas as naçóes seguiram os passos dos negociadores reunidos na COP 15, ansiosos por um consenso em torno de um acordo global ambicioso para o período pós-2012. Seu objetivo maior que é "a estabilização das concentraçóes de gases de efeito estufa na atmosfera em níveis que permitam evitar interferências perigosas sobre o sistema climático global".

Garcia (apud GUIMARAES, 2000) revela:

A educação ambiental deve ser uma concepção totalizadora de Educação e que é possível quando resulta de um projeto político-pedagógico orgânico, construído coletivamente na interaçáo escola e comunidade, e articulado com os movimentos populares organizados comprometidos com a preservaçấo da vida em seu sentido mais profundo. (p. 68).

Seria, portanto, com o auxilio da escola, que a educação ambiental assumiria verdadeiramente a sua função, a de aprofundar conhecimentos sobre questóes ambientais, como também criar espaços para a participação coletiva, ressaltando princípios e valores éticos que integrem o homem moderno à natureza.

A educação ambiental tem por escopo desenvolver a hegemonia popular, a transformação do contexto social, e não reproduzi-lo de modo a fazer os cidadãos máquinas destrutivas da natureza. Então, como componente de cidadania, a educação ambiental implica em novos métodos de ensino, novos saberes, que sejam proficientes e compreendam a complexa relação homem/natureza.

\section{CONSIDERAÇÓES FINAIS}

Após, a discussão aqui proposta, se faz necessário atentar para a função que deve assumir a própria sociedade em relação à educação ambiental. É ela que deve exigir políticas mais efetivas, divulgação mais ampla sobre a questão da preservação dos recursos naturais, como também se reverte da missão de cobrar de instituições privadas, em especial, o compromisso com o meio social.

Considerando-se que essas empresas se apropriam de parte do espaço concedido à sociedade, é natural que esta crie expectativas a respeito das respostas que essas organiza- ções darão a comunidade. É mais natural, ainda, a empresa atender prontamente a tais questionamentos e retribuir não só pelo espaço que a sociedade lhe oferece, mas também retribuir os recursos que a natureza lhe cede. Para que essa política de retorno se estabeleça, é fundamental que ambas as partes - sociedade e instituição - se conscientize, se proponha a novos processos de aprendizagem para que novos saberes se afirmem no contexto sociocultural.

Como cita Silvia Czapsk: "Copo meio-cheio ou meiovazio. É assim com a educação ambiental. Um simples clique num sítio de busca na internet, com a expressão-chave “educação ambiental” levará imediatamente à indicação de mais de um milhão de links. Enorme e impenetrável floresta, pode-se pensar. É o copo tão cheio, capaz de causar a desistência, antes de começar o mergulho. Ou a impressão de que tudo está realizado, frente a tão expressivo resultado. No outro extremo, eventualmente em conversa ou troca de correspondência com educadoras/es - especialmente se a pessoa estiver mais distante dos grandes centros econômicos e políticos - virá a sensação do copo vazio. Somos tantos, mas tanto há ainda por fazer, tanto por completar. Apoios que se buscam, recursos que faltam, indicaçóes certeiras nem sempre fáceis de encontrar. Muito se fez, mas muito há por fazer." (Os diferentes matizes da educação ambiental no Brasil, 2009)

Conclui-se este artigo ressaltando-se a necessidade de se rever o ideal que se encontra relacionado ao tema sustentabilidade nos tempos atuais. Precisa-se pensar em educação ambiental distanciada de sistemas políticos e econômicos, e, portanto, voltada à ética, à cidadania, à superação do reducionismo social e, principalmente, à representação da relação de dependência entre homem e natureza. Assim, se poderia reverter o quadro de devastação e de catástrofes provocados pelo próprio ser humano.

\section{AGRADECIMENTOS}

As autoras agradecem à Professora Rosana Aparecida Ravaglia Soares por ceder seu tempo revisando este trabalho e pelas orientações dadas.

\section{REFERÊNCIAS BIBLIOGRÁFICAS}

ANDRADE, R.O.B.; TACHIZAWA, T. CARVALHO, A.B. Gestão Ambiental: Enfoque estratégico aplicado ao Desenvolvimento Sustentável. Makron Books, 2002.

BRASIL, Constituição da República Federativa do. São Paulo: Saraiva, 2003. 
BRASIL, Ministério do Meio Ambiente. Os diferentes matizes da educaçáo ambiental no Brasil 1997 - 2007. Brasília:MMA, 2008.

BRASIL. Ministério da Educação. Educação Ambiental: aprendizes de sustentabilidade. Cadernos SECAD 1. Brasília: MEC, 2007.

CMMAD - COMISSÃO MUNDIAL SOBRE MEIO AMBIENTE E DESENVOLVIMENTO. Nosso futuro comum. Rio de Janeiro: Fundação Getulio Vargas, 2001.

COP15. Guia rápido. Disponível em: http://www.mudancasclimaticas.andi.org.br/cop15/node/1. Acesso em jun. 2010.

DEWES, D.; WITTCKIND, E.V. Educação ambiental para a sustentabilidade: história, conceitos e caminhos. Rio Grande do Sul: Campus Santo Ângelo, 2006.

ECOECO. O que é economia ecológica. Disponível em: http://www.eco.unicamp.br. Acesso em ago. 2004.

GRÜN, M. Ética e Educação Ambiental: a conexão necessária. São Paulo: Papirus, 1996.

GUIMARAES, M. Educaçáo ambiental: no consenso um embate? São Paulo: Papirus, 2000.

HERCULANO, S.C. Sociologia Ambiental: origens, enfoques metodológicos e objetos. In: Revista Mundo e Vida: alternativas em estudos ambientais, Niterói/RJ, ano I, no 1, UFF/PGCA-Riocor, 2000, pp. $45-55$.

JACOBI, P. Educação Ambiental, Cidadania e sustentabilidade. Cadernos de Pesquisa. São Paulo: USP, 2003.

UNESCO. Projeto do milênio das Naçóes Unidas 2005 Investindo no desenvolvimento: um plano prático para atingir os objetivos de desenvolvimento do milênio. Visão geral. Nova Iorque, 2005.

UNESCO. Decenio de las Naciones Unidas de la Educación con miras al Desarrollo Sostenible (2005-2014): Plan de aplicación internacional. França, 2006. 